Pedagogía y Saberes No. 51

Universidad Pedagógica Nacional

Facultad de Educación. 2019. pp. 103-112

\title{
La educación en la era de lo securitario: el declive de la disciplina*
}

Artículo de investigación

Education in the Security era: the Decline of the Discipline A educação na era do securitário: o declínio da disciplina

Carlos E. Valenzuela E.**

Para citar este artículo:

Valenzuela, C. (2019). La educación en la era de lo securitario: el declive de la disciplina. Pedagogía y Saberes, 51, 103-112.

** Este artículo deriva de la investigación -en curso- que fundamenta la tesis doctoral sobre la relación herencia - educación en el Doctorado Interinstitucional en Educación DIE-UPN.

*** Estudiante del Doctorado Interinstitucional en Educación de la Universidad Pedagógica Nacional y profesor Titular de la Universidad Pedagógica Nacional (UPN).

Correo electrónico: cvalenzuela@ pedagogica.edu.co.

Perfil oRCID: orcid.org/0000-0003-3326-3686 


\title{
Resumen
}

Este artículo de investigación presenta una reflexión en clave pedagógica sobre la crisis del concepto de disciplina en la escuela contemporánea, alineada cada vez más a un régimen liberal a causa del fenómeno de des-institucionalización por el que atraviesa en la actualidad. En ese orden de ideas, el texto comienza con la descripción de la categoría disciplina, revelando el peso de esta en la constitución de lo humano; luego, caracteriza su declive en lo escolar como consecuencia del desfondamiento que hoy sufren las instituciones en el marco de las sociedades de seguridad y, finalmente, termina presentando los efectos de la era de lo securitario en la educación y la pedagogía, con sus subsecuentes repercusiones en la enseñanza.

\section{Palabras clave}

pedagogía; hábito; escuela; regla

\begin{abstract}
This research article presents a pedagogical reflection on the crisis of the concept of discipline in the contemporary school, increasingly aligned with a liberal regime due to of the phenomenon of deinstitutionalization that it is currently experiencing. In this order of ideas, the text begins with the description of the discipline category, revealing its weight in the constitution of the human; then, it characterizes its decline in school as a result of the setbacks that institutions suffer today within the framework of security societies and, finally, ends by presenting the effects of the era of the security in education and pedagogy, with its subsequent repercussions in education.
\end{abstract}

\section{Keywords}

pedagogy; habit; school; rule

\section{Resumo}

Este artigo de pesquisa apresenta uma reflexão pedagógica sobre a crise do conceito de disciplina na escola contemporânea, cada vez mais alinhada com um regime liberal, devido ao fenômeno da desinstitucionalização que está vivenciando atualmente. Nessa ordem de ideias, o texto começa com a descrição da categoria disciplina, revelando seu peso na constituição do humano; depois, caracteriza seu declínio na escola como resultado da quebra que as instituições sofrem hoje no âmbito das sociedades de segurança e, finalmente, finda apresentando os efeitos da era da segurança na educação e na pedagogia, com suas consequentes repercussões na educação.

\section{Palavras-chave}

pedagogia; hábito; escola; regra 


\section{La disciplina}

Nos hacemos humanos en virtud de la educación que recibimos a lo largo de nuestra existencia, pues, a diferencia de lo que se piensa de modo usual, tanto el cuidado del que somos objeto al comenzar a vivir como las lecciones que nos confieren con el paso del tiempo a través de la instrucción, forman parte de la educación, concebida por Kant ([1803] 2003) en términos de cuidados y formación. Por consiguiente, los adagios de papá en materia de conducta serían tan educativos como las explicaciones dadas por los maestros de matemática en la escuela; solo que, claramente, con arreglo a propósitos distintos. De allí que no quepa ensalzar la instrucción en detrimento de la disciplina, pues, esta es considerada condición de posibilidad de la primera: "la falta de disciplina es un mal mayor que la falta de cultura; esta puede adquirirse más tarde, mientras que la barbarie no puede corregirse nunca" (p. 32).

Así las cosas, de no ser por la disciplina, nuestro futuro estaría igual de fijado que el de los animales, pero por razones diferentes. Los animales arriban al mundo "hechos". Se conducen con base en lo que sus genes dictan. La naturaleza misma se encarga de su regulación, regulándose ella a sí misma, al disponer de su existencia. El hombre, en cambio, solo puede sobrevivir a expensas de otro que lo acoja, alguien que, con sus cuidados, le suministre al recién llegado la oportunidad de valerse por sí mismo mediante la costumbre, el hábito, la disciplina, con el fin de no ser dependiente; independencia que solo se consigue a fuerza de aprender a someter la pulsión, de manera que la razón sea la responsable de conducirle y no la barbarie. ${ }^{1}$

Y de la barbarie sería fácil ser presa, de no ser por la disciplina, aquella a la que se subordina la instrucción en función del fin al que aspira: un cuerpo adiestrado, una mente concentrada, "[un] hombre que lucha consigo mismo, preocupado por su propia forma" (Sloterdijk, 2012, p. 25). Ahora, la aparente ironía que encierra la acción de someterse para "emanciparse", al fin, de la libertad a la que somos proclives por naturaleza, no entraña de fondo paradoja alguna,

1 "La naturaleza y la cultura estarían unidas, de antemano, por un amplio espacio de en medio, de prácticas corporeizadas, donde encuentran su sitio las lenguas, los rituales y el manejo de la técnica, en tanto estas instancias materializan las formas universales de un conjunto de artificios automatizados. Tal zona intermedia constituye una región pródiga en formas, variable y estable, que provisionalmente puede ser designada con suficiente claridad mediante expresiones convencionales como educación, usos, costumbres, conformación de hábitos, entrenamientos y ejercicios". (Sloterdijk, 2012, p. 26) pues, dichas leyes, al sujetarnos, nos alejan del previsible sino al que están condenadas todas las demás especies sin saberlo.

Nosotros, en cambio, al regularnos mediante las disciplinas, nos hemos hecho capaces de invertir tal energía en producirnos a nosotros mismos. Así las cosas, se constata cómo las disciplinas no solo contribuyeron a la emergencia de lo social en virtud del peso que ejercieron sobre la administración de lo humano, también tributaron al mantenimiento de tal orden de cosas mediante la instauración de mecanismos educativos consagrados a la fabricación de dicha humanidad. La escuela aparece así, al igual que otras instituciones, como efecto del ideal moderno, cifrado en el cometido de producir un nuevo mundo y con él a sus pobladores, es decir, al ciudadano bajo la égida de un Estado-nación.

La disciplina, entonces, lejos de ser un efecto de lo social - que, se supone, le precedería - es inmanente a él, por tanto, su condición - la de la disciplina- es antropotécnica ${ }^{2}$ por excelencia. Es decir, la emergencia de lo humano responde a una manera de operar del hombre consigo mismo cuyo efecto rebasa, por lo general, el saldo inicial.

De esta manera, la disciplina así entendida comportaría el germen de lo humano, lo cual la haría condición de posibilidad no solo de aprender a conducirnos sino, además, de construir nuevos horizontes de existencia. De allí que la disciplina en tanto técnica de gobierno, constitutiva de lo humano, no dejase de ocupar un papel esencial en relación con la dirección de las poblaciones, sirviendo así, en el contexto de la modernidad, a los intereses del Estado y sus diferentes instituciones. Su emergencia, de hecho, data desde mucho antes del siglo XV, digamos, desde las técnicas empleadas por los monjes en las comunidades monacales, aún más, desde la vida de los pastores hebreos, es decir, desde hace ya milenios.

Mediante estas técnicas, pues, se cristalizará la condición de lo social, la posibilidad de vivir juntos. A ellas se acudirá para efectos de guiar a la población, aquella heterogeneidad de individualidades que requerirá urgentemente de gobierno. El estallido demográfico y las revueltas que a ella vienen aparejadas justificarán la emergencia de la población leída en términos de un conjunto de asuntos que implica o demanda administración.

2 Señala Sloterdijk (2012) al respecto: “(...) entiendo [por antropotécnica] los procedimientos de ejercitación, físicos y mentales, con los que los hombres de las culturas más dispares han intentado optimizar su estado inmunológico frente a los vagos riesgos de la vida y las agudas certezas de la muerte" (p. 24). 
Así, el Estado, la institución moderna por antonomasia, vendría a ser una institución que se configuraría en razón del problema que la población representaba. Por lo tanto, más allá de pensar las disciplinas en términos de amenazas contra la libertad, estas se constituirán en potentes artefactos mediante los cuales se tendría ocasión de hacer cuerpo social, de producir juntos en función de lo propio y lo común; de generar oportunidades de estar cerca sin aniquilarse. Aún más, de construir, a expensas incluso del carácter circunspecto y reglado de la disciplina, o quizá en virtud de él, inéditas posibilidades de ser sujeto y de estar con otros.

También de hacer con otros en atención a unas reglas, no a unas leyes, pues, las primeras tienen que ver con el modo de vida práctico y, en consecuencia, rigen con arreglo al despliegue de las disciplinas y sus finalidades. Las segundas se muestran ajenas al modo de obrar que tiene lugar en el seno de las disciplinas.

Así las cosas, las reglas terminan por ser configuradoras de disciplina, y esta, a su vez, se distingue por imprimirle sentido y propósito a las reglas en virtud de lo que allí se juega. Las leyes, en cambio, no atienden al ethos del modo de vida práctico, de hecho, hacen abstracción de él para poder reinar desde la soberanía de lo trascendente. Al respecto, vale la pena plantear lo siguiente:

Baudrillard señala que lo que se opone a la ley no es la ausencia de ley sino la regla. La regla opera donde no hay lenguaje analógico. ¿Cuál es el estatuto de la regla? No se trata de leyes trascendentes sino de reglas inmanentes. La fuerza de la regla parece residir en su capacidad de constituir un orden convencional de juego. En definitiva, se trata de la constitución de un juego donde ningún jugador debe ser más grande que él. (Lewkowicz, 2004, p. 37).

Precisamente esta última idea concerniente al juego tiene un claro aire de familia con respecto al sustrato ascético de las disciplinas, relativo a la ejercitación y el hábito; otro par de conceptos decisivo a la hora de entender lo concedido por las disciplinas al surgimiento de la modernidad, pues, la ejercitación:

(...) se encuentra en el centro de una de las primeras formas de vida colectivas modernas en la cual los sujetos trabajaban en beneficio propio y en función del Estado y sus instituciones; tal relación fortaleció los procesos de individualización y los de institucionalización de las funciones y relaciones sociales, y supuso el fortalecimiento de técnicas y estrategias disciplinarias orientadas a la producción de individuos y grupos humanos gobernables. (Marín-Díaz, 2018, p. 3).
Así, pensar que las formas de vida modernas acabaron por hallar su condición de posibilidad en el seno de técnicas milenarias, nos revela cuan alta sigue siendo nuestra deuda en relación con la educación en tanto conjunto de estrategias disciplinarias destinado a la producción de lo humano. De allí la acertada referencia a Sloterdijk (2012) para quien el ser humano no es más que un animal técnico en virtud de ser, él mismo, una producción técnica. Ahora, si bien la finalidad en función de la cual han operado a lo largo de los siglos las disciplinas ha variado, el grado de subordinación al que estas nos han sometido parece no haber cambiado; seguimos siendo seres ejercitantes por definición.

De este modo, se pone de relieve el carácter constitutivo de la disciplina, aquella a cuyo operar obedecería nada más y nada menos que la invención de lo social. Es decir, la sociedad civil, aquel escenario que asumimos de modo convencional en calidad de espacio autónomo respecto del Estado, no sería más que una suerte de antropotécnica moderna. Podría decirse que somos fruto de las disciplinas; nos hemos servido de ellas tanto como ellas de nosotros, pues, si bien tuvieron lugar gracias al ingenio humano, de no ser por ellas, jamás habría emergido la idea moderna de individuo y sociedad. Y tampoco habríamos contado con la maquinaria institucional necesaria para la producción de tales seres humanos. En consecuencia, la disciplina, por esta vía de conceptualización, más allá de ser un mero instrumento de coacción y termina elevándose a la categoría de instancia productora de lo humano.

Lo anterior revela el fuerte protagonismo atribuido por las instituciones modernas a las disciplinas, en tanto técnicas responsables de organizar y controlar, en función del bien común, el conjunto de relaciones que se da entre los individuos poseedores de un cierto grado de libertad. Este margen de autonomía se regula, fija, limita y concentra con el fin de tornarlo productivo, haciendo, a la par, de aquel que lo concede, digamos, un asceta, alguien dueño de sí, capaz de superar la barbarie a través de la ejercitación, el hábito, la costumbre:

(...) El poder de la costumbre no es entendido meramente como un estar subyugado por las rutinas, sino como un principio generador de la acción anclado en lo prepersonal. Cuando los escolásticos hablaban de habitus lo entienden como una disposición, como la del Jano bifronte, que, con una cara mira hacia atrás, a la serie de acciones similares del pasado, en las que ella ha tomado cuerpo, mientras que con la otra cara mira hacia adelante, a las próximas ocasiones donde debe acreditarse de nuevo. El habitus constituye con ello, una potencia 
que se ha ido formando a partir de actos anteriores y que se actualiza en actos renovados. (Sloterdijk, 2012, p. 238).

Hábito, he aquí otra palabra del argot educativo al parecer en desuso, carente de valor pedagógico y confinado al panteón de la modernidad por la lógica neoliberal y su consigna del "aprender a aprender". Podría decirse que el hábito ha pasado de ser un efecto deseado por los maestros con el propósito de internalizar y potenciar una técnica, a convertirse para muchos en un anacronismo sin lugar en el glosario de la educación contemporánea.

La idea de interrumpir el flujo incesante de pulsiones al que cada uno de nosotros equivale en calidad de ser hablante mediante el hábito, efecto de la educación, ha hecho de esta un gran dique cuya administración es ejercida por un Otro que, entre más ignora cuan dependientes somos de la disciplina, más infructuosa torna su propia acción educativa.

Una labor que, de acuerdo con Locke ([1690] 2012) y Kant ([1803] 2003), no se restringiría al plano del conocimiento o al campo intelectual; pues su enfoque ha de contemplar también otras dimensiones que van más allá de la instrucción. Y es justo gracias a esa complejidad que la educación revela, que no cabe hablar de ella desde un solo ángulo, el del saber enciclopédico (modo sofístico), por ejemplo, sino también desde el saber espiritual (modo socrático) (Noguera-Ramírez, 2012). En ese orden de ideas, al evocar conceptos como el de disciplina y hábito, recordamos concomitantemente asuntos que el común de nosotros parece haber olvidado, relativos al trabajo imperativo que a diario hemos de acometer con aquella fuerza vital e informe que todo recién llegado comporta al nacer.

Energía que solemos escindir del cuerpo como consecuencia del énfasis puesto hoy por hoy en la conciencia, cuando en realidad dicha amalgama lo es todo: "Mens sana in corpore sano, (...) una descripción breve, pero completa de un estado feliz en este mundo" (Locke [1690] 2012, p. 31). Por consiguiente, la educación constituiría un conjunto de técnicas para el cual mente y cuerpo; hábito y raciocinio; mano y cerebro conforman una mezcla cuyo fin apunta a la conducción de aquel veleidoso sujeto que oscila a lo largo de su vida, pero en especial en sus primeros años, entre el deleite sin freno de la pulsión y el austero límite de la razón, a la que se espera, sea proclive siempre como consecuencia del acto formativo.

Alcanzar dicho propósito, claro está, no es considerada tarea fácil, pues, reclama tanto del que la plantea como del que la requiere: fuerza, virtud, compromiso, disciplina; y no solo intelecto, pues, este de nada sirve cuando no se posee el temple y el tesón que demanda la contemplación de lo inteligible. Tal es el destino que Locke, por ejemplo, le augura a aquel capaz de domeñar los deseos que empujan al infante a desbordarse, entregándose sin más a sus caprichos. Nada conjura mejor tan perversas inclinaciones, dirá Locke, que la incorporación del hábito, el cual no emerge a partir del interés del niño por hacer de sí alguien cada vez mejor, lo que no resultaría esperable de alguien que apenas si es consciente de sí mismo. El hábito, en cambio, tiene lugar gracias a la injerencia de una autoridad, de cara a la cual se precisa obediencia y sumisión, infundidas de manera clara al fustigar con tacto y vehemencia al niño:

Si los padres han sabido, por medio de una dirección firme, hacer complaciente y flexible la voluntad de sus hijos, antes de que tengan memoria para recordar los comienzos, les parecerán estos naturales, y actuarán, por otra parte, en ellos como si lo fueran en efecto, y prevendrán así toda ocasión de resistencia y revuelta. Es preciso solamente tener cuidado de comenzar pronto y mostrarse inflexible hasta que el temor y el respeto se hayan hecho sentimientos familiares para el niño y no se sienta el menor esfuerzo en la sumisión, en la obediencia espontánea de su espíritu. (Locke [1690] 2012, p. 75).

Para la escuela actual dichas reglas no constituirían más que la alegoría de una etapa ya superada a la que no cabría volver de querer ser consecuentes con el espíritu pedagógico de nuestra época, la cual dicta algo opuesto a la "mano dura", defendida por Locke ([1690] 2012), para quien la extrema indulgencia no acarrea sino problemas para la educación del niño, al que tampoco, aclara el filósofo inglés, cabría atacar mediante castigos infundados cuyo único fruto sería el del miedo a la autoridad paterna sin más, materia prima del servilismo y la sumisión, pues:

(...) si el espíritu del niño se halla demasiado humillado y servil, si sus facultades se hallan demasiado abatidas y enervadas por el exceso de una disciplina demasiado rigurosa, pierden todo su vigor, toda su actividad, y caen en un estado peor que el precedente. (Locke ([1690] 2012, p. 76).

De esta forma, la escuela, pese a la serie de imprecaciones que a diario recae sobre ella, reclamándole cambiar, no haya otra manera de atender a su cometido que a través de distintas técnicas disciplinarias como la celular, orgánica o genética con sus correlatos en la vigilancia jerárquica, la sanción normalizadora y el examen, al fin y al cabo, la disciplina, más allá de toda imposición, es condición de posibilidad, de ahí 
su filiación o dependencia a la regla ya que a través de ella lo que se busca es producir condiciones para el encuentro. Dice Lewkowicz (2004):

(...) la noción de regla supone un tipo de subjetividad, un tipo de situación, un tipo de regulación. Su punto de partida es la ausencia de regulación, la anomia. Ahora bien, la producción de reglas no es producción de reglas discrecionales sino producción de condiciones para un encuentro. Si hay discrecionalidad o abuso estamos en otro terreno. (p. 37-38).

Así, sin regla no habría manera de estar juntos; no habría manera de enseñar nada a nadie. Sin el sometimiento al que obliga la disciplina, vía la ejercitación y el hábito, nada se produciría, ni siquiera sujeto, pues, no habría que lo interpelara.

Aquella creatividad por la que tanto abogan los discursos innovadores, por ejemplo, requiere más que ninguna otra cosa de sometimiento, de subordinación a esa misma regla que, paradójicamente, ellos no dudan en proscribir. Crear en medio de la anomia a la que invita la lógica del "dejar hacer" es imposible. La genialidad que por ejemplo, le atribuimos a los astros del deporte no es producto de un golpe de suerte, es el efecto de una vida dedicada a la ejercitación.

Ahora, ante lo que algunos describen como el final de las disciplinas y la ejercitación, cabe preguntarse en consecuencia: ¿a qué se asiste hoy? ¿A la abolición de las disciplinas $y$, por tanto, de sus efectos o a una reconfiguración de sus fines? 0, aún más, ¿a una reconversión del propio régimen disciplinario? Veamos.

\section{De la crisis de lo disciplinar al arribo de lo securitario en la escuela}

De acuerdo con lo anterior, la disciplina, afín a la costumbre y el hábito por su carácter ejercitante, no es hoy por hoy de muy buen recibo entre los discursos pedagógicos contemporáneos, pues, estos la declaran indeseable en virtud de las nuevas consignas a las que empuja el presente neoliberal. Consignas que entran a minar el suelo de las instituciones disciplinarias, restándoles no solo credibilidad, sino también, injerencia y peso. De allí el desfondamiento al que se ve sometida la escuela como consecuencia del desmoronamiento del que, a su vez, viene siendo objeto el Estado-nación (Lewkowicz, 2004).

Ahora la proclama pedagógica contemporánea se alinea al deseo de gozar de aquella libertad que la enseñanza, al confinarnos a un tiempo y espacio determinados; al imponernos un saber; al instaurar unas reglas; al abocarnos a una autoridad, nos expropió tiempo atrás.

La idea de aprender lo que a bien tengamos, a la hora que deseemos y donde nos plazca ratifica justo aquel presupuesto de libertad sin límites que enarbola tanto el neoliberalismo como las más arbitrarias lecturas del constructivismo y la escuela nueva. Así las cosas, el disciplinamiento como técnica destinada en el marco de la escuela a la producción de sujetos, responsables de sí y de cuanto los precede, pero también "de lo por-venir, como acontecimiento imprevisible al que podemos dar lugar" (Valenzuela, 2017, p. 82), ve ahora su ocaso en virtud de la crítica hecha por tales discursos a conceptos tan fundamentales para la pedagogía como "[el] ejercicio, el hábito, la costumbre y la repetición" (Noguera-Ramírez, 2017, p. 29).

Sin embargo, consecuentes con el hecho de asumir al hombre, de acuerdo con Sloterdijk (2012), como un producto, efecto de ciertas maniobras técnicas, por más desplazamiento al que sea sometida la disciplina hoy, la operación técnica sobre lo humano con el objeto de producirle no puede cesar, pues de ella somos deriva.

En consecuencia, lo que afrontamos en la contemporaneidad no es una dejación de la antropotécnica en sí misma, sino una suerte de permutación en sus fines, con su respectiva connotación en los modos de operar sobre lo humano, gracias a los cuales el énfasis disciplinar del tipo de sociedad tradicional - hegemónico a lo largo de muchos años y aún en el presente-comienza a coexistir, aunque restándose de hecho protagonismo, con uno de carácter liberal o securitario, el cual no emerge a costa de los dispositivos disciplinares de la sociedad tradicional, pues, más allá de abolirlos, "estas sociedades de seguridad [los] abarcan, utilizan, explotan y perfeccionan sin suprimirlos" (Lazzarato, 2007, p. 87).

De manera que la crítica contra lo disciplinar en la escuela hoy, ¿equivaldría acaso, al mismo tiempo, a un reposicionamiento de lo securitario? De ser así, ¿cuáles serían las señales propias en la escuela? Esclarecerlas supone conocer las diferencias que habría entre disciplina y seguridad.

La disciplina encierra, fija límites y fronteras, mientras que la seguridad garantiza la circulación. La disciplina impide, la seguridad permite, incita, favorece y solicita. La primera limita la libertad, la segunda - dice Foucault- es productora de libertad. La disciplina es centrípeta, concentra y encierra; la seguridad es centrífuga porque lo que 
hace es ampliarse para integrar incesantemente nuevos elementos en el arte de gobernar. (Lazzarato, 2007, p. 87).

De acuerdo con tal distinción, la fractura de lo disciplinar en términos de la renuncia al límite; del reparo a la posibilidad de congregarse en torno de un saber y en el marco de un espacio; de la renuencia a la oportunidad de ser interpelado de manera que no todo esté permitido, revelaría, más que una transición, una clara oscilación de la escuela entre la disciplina y la seguridad, con una cada vez más notoria tendencia hacia esta última. Este hecho invita a reflexionar como mínimo sobre las implicancias pedagógicas de dicha fluctuación para la educación hoy, pues, no basta con reivindicar el lugar de la disciplina, ni con denunciar las críticas hacia esta desde los discursos contemporáneos.

El trabajo ahora quizá radique en analizar, desde el ángulo pedagógico, no solo las manifestaciones de lo securitario en el plano de la institución escolar, sino además, el lugar funcional de lo disciplinar en relación con tal estado de cosas. Tarea por demás nada sencilla dada la complejidad que estas nuevas técnicas de gobierno reportan con respecto a su dilucidación.

Todavía tenemos una concepción disciplinaria de la sociedad, pensamos en el presente a partir de los sujetos que se constituyen en la sociedad disciplinaria, mientras que en este segundo tipo de sociedades [securitario] es más difícil comprender y determinar el proceso de subjetivación. Todas las formas de organización social y política con las que hoy se combate este tipo de control emergen de las sociedades disciplinarias, tales como las luchas clásicas, la lucha obrera, la concepción misma del poder. Por eso tenemos tanta dificultad para entender la fórmula de la acción sobre las acciones posibles, y es que tenemos la impresión de ser más libres en la sociedad de seguridad que en la sociedad disciplinaria. Pienso que lo fundamental es que ahora en los procesos sociales no se interviene para bloquearlos, encerrarlos, fijarlos, delimitarlos. Más bien se los toma tal cual; no decimos si son buenos o malos, se trata más bien de hacer una cartografía de lo que pasa. Ahora bien, después de hacer esta cartografía, se interviene dentro de lo que sucede para jugar con los componentes de lo que sucede; de modo que tenemos aquí una técnica de gobierno totalmente diferente. (Lazzarato, 2007, p. 91-92).

Hablamos de una nueva antropotécnica cuya imbricación en la formación de los sujetos parece mostrar otras variantes, más centradas en lo que el individuo hace que en su propio cuerpo, pues, aquí se actúa,
(...) sobre la acción del individuo, y sin duda esto es muy diferente; porque cuando se trata de la acción, el individuo no es el origen absoluto de la acción; por consiguiente, se interviene sobre toda una serie de elementos que determinan la acción. (Lazzarato, 2007 p. 90).

En este escenario la lógica disciplinar se invierte por cuanto ahora, de acuerdo con Lazzarato (2007), se opera sobre un espacio abierto, en el que confluyen el individuo y un campo de acciones posibles, campo sobre el que se interviene; mientras que "en el régimen disciplinario el campo de acción está completamente estructurado: por ejemplo, en la escuela podemos determinar el espacio y el tiempo, el lugar del estudiante, el lugar del profesor, el tiempo que da ritmo a la vida escolar" (pp. 90-91), por tanto, enfrentaríamos aquí no una supuesta liberación del yugo al que la disciplina nos condenaba, vía la ruptura de lo instituido, sino un nuevo proceso de sometimiento cuya fisonomía no resulta del todo clara para muchos. Aún más, buena parte de los discursos pedagógicos contemporáneos ni siquiera le advierten y creen estar atestiguando ${ }_{\iota}$ por el contrario, una salida al sometimiento.

Un viejo problema de los docentes era cómo ir más allá de lo instituido, cómo ir más allá de dictar clase, cómo salir del aula como espacio burocrático, rutinario, autoritario, etcétera. Estamos de nuevo en la lógica del Estado, de la cual hay que ir más allá. Pero el galpón es otra cosa. ${ }^{3}$ En el galpón, el problema es ante todo cómo se instituye algo, y no cómo se va más allá de lo instituido. Para esto, uno de los problemas es que no hay reglas institucionales más o menos precisas. (...) En el aula - tomada como situación y no como parte de una institución- se ponen (y no se suponen) reglas para compartir, para operar, para habitar y no leyes trascendentes que rijan de antemano. En condiciones de galpón, la única institución es la precariedad de la regla compartida, y no la ley trascendente. La regla es inmanente, precaria, temporaria, se pone para un fin, no preexiste, no se supone, es más regla de juego que ley del Estado. (Lewkowicz, 2004, pp. 35-36).

Se puede apreciar entonces, en apariencia, una nueva gramática en la escuela - liberal quizá - cuya lógica, más que mostrarse ajena a los imperativos de lo instituido, los recicla con el objeto de avanzar en el juego de lo provisorio al que nos arrastra el galpón.

3 "Esto es, un tipo de funcionamiento ciego a la destitución de la lógica estatal y a la instalación de la dinámica de mercado. Vale decir que esta ceguera compone un cuadro de situación donde prosperan suposiciones que no son tales, subjetividades desvinculadas, representaciones e ideales anacrónicos, desregulaciones legitimadas en nombre de la libertad, opiniones varias, etcétera" (Lewkowicz, 2004, p. 32). 
Una interesante metáfora que resulta hasta cierto punto alegórica de la crisis por la que atraviesa la disciplina hoy, y con ella, obviamente, la escuela en virtud de su linaje moderno. No obstante, si aceptamos la tesis de Lewkowicz, según la cual, la educación ya no es lo que era, vale la pena sin duda comenzar a preguntarnos con él por su estatuto actual en el marco de la era securitaria.

\section{¿Educación prohibida o prohibido educar?}

La economía de sentido mediante la cual solemos referirnos en la actualidad a la educación hace que ignoremos la complejidad que dicho concepto posee. Hablar de educación para muchos hoy no pasa de ser un pasatiempo. Hablan de ella políticos, periodistas, documentalistas y hasta empresarios, arrogándose el derecho, al hacerlo, de decir cualquier cosa al respecto con el propósito de buscar votos, audiencia o clientes. Y por lo regular, obtienen lo que buscan, pues, para la gente en general la educación no es otra cosa que un lugar común. A la larga, lo mucho o poco que se predique en relación con la educación, en tanto noción vaciada de sentido, no marcará la diferencia, pues, se da por sentado que todos sabemos a qué nos estamos refiriendo. Más aún quienes a ella nos dedicamos.

Pero, ¿así es? ¿Se ha vuelto, acaso, también un lugar común entre nosotros? ¿Uno tan común, incluso, que hemos dejado de prestarle atención? Tal vez. Y quizá por esa vía hemos contribuido a hacer de la educación un fetiche. Un asunto al que todos, sin distingo y al unísono, queremos aportar, pues, de eso se trata. De tributar a la educación, no de someterla al escrutinio del pensamiento. La idealización que sobre la voz educación se ha volcado ha hecho de esta un objeto reificado al que no cabe sino rendirle culto; una consigna mediante la cual unos y otros se justifican; una leyenda acerca de la cual todos quieren oír hablar; una verdadera zona de confort a la que se accede, hoy más que nunca, sin pagar derecho de entrada alguno.

Así las cosas, lo que llamo aquí "el fetiche de la educación" no sería otra cosa que una manera de entender tal concepto que, sin hacer explícito un lugar objetivo de enunciación, instaura respecto de él juicios de valor del más diverso orden. Juicios mediante los cuales se popularizan nociones generales sobre la educación que, "al funcionar como proverbios difícilmente negables porque son susceptibles de ser validados en la misma medida en que pueden ser refutados y llenados con valores diversos de acuerdo con el parecer de quien los oye, producen un consenso aparente" (Leme Britto, 2010, p. 35).
Consentimiento del que, por supuesto, derivan multiplicidad de mitos vulgares sobre los que bien valdría la pena detenerse con el propósito de conjurarles o, al menos, develar su carácter reificado, omitido, por lo general, por quienes han hecho de tales adagios su caballito de batalla. He aquí uno:

Yo creo que es importante no esperar que un gurú, un maestro, nos vaya a decir cuál es el camino, sino que el maestro más bien tiene que transitar de ser protagonista a desaparecer porque creo que el protagonista de la vida de cada cual es cada cual, ¿cierto?

La anterior sentencia, extraída de uno de los programas de Historias con Futuro en el que entrevistan a una doctora en Educación, forma parte de aquella vulgata pedagógica (Meirieu, 2016) referida líneas atrás. Una idea que, además, se patrocina como revolucionaria en virtud del hálito al parecer novedoso que la acompaña, cuando en realidad, su génesis data de hace ya 1600 años.

De este modo, a expensas de un punto de vista espurio, no se hace otra cosa que proferir "máximas" que, a la postre, solo dejan translucir cuan cómodo les resulta a muchos hablar de educación desde cualquier lugar. Entre otras cosas porque saben muy bien quienes lo hacen que contarán de seguro con la aquiescencia de la mayoría, pues, esta tal vez piensa lo mismo: que ahora al maestro solo le resta "dejar aprender" y desaparecer, consigna esta de cuño claramente neoliberal que se sintoniza bastante bien con el declive de la disciplina.

Educar hoy, entonces, al amparo de la disciplina y guiados por la enseñanza no es algo que se muestre del todo consecuente en relación con la lógica securitaria arriba descrita, régimen para el cual no cabe ya suponer que en la escuela, estudiantes, directivos y maestros van a proceder con base en lo prescrito por el Estado-nación y sus instituciones. Los presupuestos de lo securitario parecen ser otros y distan por supuesto de aquella concepción disciplinaria de sociedad a partir de la cual constituíamos sujeto. Ahora, los procesos de subjetivación propios de este tipo de sociedad, leídos en una clave (la disciplinar) que les tilda de anómalos o deficitarios, no obedecen, de acuerdo con Lewkowicz (2004), a tropiezos en las aspiraciones de institucionalidad, responden más bien al ocaso de una lógica, la disciplinar, cuyas fisuras son aprovechadas por lo securitario de muy diversas formas. $Y$ a pesar de la dificultad que reporta el hecho de tratar de comprender tales procesos de subjetivación (Lazzarato, 2007), su despliegue arroja ya pistas susceptibles de aprehender. Dice Lewkowicz (2004): 
Si la subjetividad institucional, producida por los dispositivos disciplinarios de los Estados nacionales, operaba como puente facilitador de las relaciones, hoy no hay nada equivalente a esa metasubjetividad, a esas operaciones básicas que simplificaban el ingreso a un dispositivo. Más bien sucede lo contrario: la subjetividad dominante no es institucional sino massmediática. En este sentido, sus operaciones básicas no son disciplinares sino otras. No se trata de normativa y saber, sino de imagen y opinión personal. (p. 35).

Ahora, nuestra voluntad ha de someterse, no a la razón, como indicase Locke ([1690] 2012), ${ }^{4}$ sino a la tiranía del "sé tú mismo", sentencia mediante la cual el mercado azuza la pulsión, exhortando a infringir el límite, es decir, a no ser "como todos los demás", pues, "lo que mejor se vende es la diferencia y no la semejanza” (Bauman, 2007, pp. 39-40). Así, nos iguala el querer ser diferentes. ¿Diferentes de...? Quizá de lo instituido, de lo habitual, de lo pretérito como si separarnos de lo viejo resolviese algún problema (Dewey, 2010). Nos sentimos inmunes al pasado, creyendo que el plus radica hoy por hoy en barajar conocimientos novedosos frente a los evidentes problemas del presente, como si estos hubiesen nacido de la noche a la mañana:

(...) No puede comprenderse la naturaleza de los problemas si no sabemos cómo han nacido estos. Las instituciones y costumbres que existen en el presente y que dan origen a los presentes males y dislocaciones sociales, no han surgido de la noche a la mañana. Tienen una larga historia tras sí. La tentativa de estudiarlos simplemente sobre la base de lo que es evidente en el presente está condenada a caer en la adopción de medidas superficiales, que al fin solo harán más agudos y difíciles de resolver los problemas existentes. La política basada simplemente sobre el conocimiento del presente separado del pasado es la contrapartida del abandono y descuido en la conducta individual. (Dewey, 2010, p. 115).

Así, divorciados del pasado por aspirar a ser diferentes en el presente, sin importar las consecuencias, caemos sin advertirlo de modo vertiginoso hacia adelante: "hemos atracado por fin en la isla de la libertad y quemado el barco que nos trajo a ella" (Sloterdijk, 2015, p. 77). A lo que Meirieu responderá: "estamos embarcados... con nuestros hijos. Y no es el momento de abandonar el barco" (2010, p. 219). Para los par-

4 "El que no haya contraído el hábito de someter su voluntad a la razón de los demás cuando era joven, hallará gran trabajo en someterse a su propia razón cuando tenga edad de hacer uso de ella. Y ¿qué hombre será un niño educado así? Es fácil preverlo"(Locke, p. 68). tidarios de la licuefacción posmoderna, entonces, lo más probable es que reparar en el atrás se considere una desventaja (Bauman, 2007) pese al hecho de considerar con Dewey (2010) que "(..) las realizaciones del pasado ofrecen el único medio de que disponemos para comprender el presente" (p. 114).

Pero es justamente la comprensión la que hoy sale perdiendo ante la sobreestimulación del progreso tecnológico y massmediático. El guiño a la fórmula responde a ese querer "saber sin aprender o, mejor dicho, lograr sin comprender" (Meirieu, 2010, p. 187). El atajo del prematuro "logro inmediato" en esta época reemplazaría a gusto el tortuoso y arduo camino del comprender a través del trabajo, pues, a propósito de la receta del buen emprendedor: "quien actúa demasiado lento en la eliminación de rivales se arriesga al contragolpe del destino" (Sloterdijk, 2015, p. 115). No habría en consecuencia mayor lección para el ciudadano de este tiempo que conseguir el éxito con el menor esfuerzo posible y a costa de los demás:

La llamada contemporánea a la búsqueda de la felicidad y el éxito personal está en esta perspectiva. Igualmente sucede con la idea de pensar al humano como un aprendiz permanente, como un empresario de su propio capital humano cuyo éxito o fracaso solo depende de la calidad de sus elecciones y de sus habilidades para dejar fuera de juego a sus competidores. (Noguera-Ramírez, 2017, p. 30).

En Caosmosis, de otro lado, Guattari (1996) hace una observación muy aguda que permite entrever el alcance de sus teorizaciones con relación al tema de la producción de la subjetividad en el régimen liberal: "(...) fue un grave error de la corriente estructuralista pretender situar todo lo concerniente al psiquismo bajo la única batuta del significante lingüístico" (p. 15).

La producción de subjetividad no se restringe ya a componentes semiológicos de agenciamiento lingüístico-significante en estricto. De hecho, hoy se pugna por una redefinición de las miradas clásicas propias del estructuralismo con respecto a los procesos de subjetivación, buscando dar entrada a otros componentes de producción distintos a la enunciación lingüística que pluralicen la génesis de la subjetividad.

De allí el resquebrajamiento de la idea tradicional de "enunciación" - distintiva de la lingüística y la filosofía del lenguaje - a la que se redujo la producción de subjetividad. Muchos hoy ya suman aspectos de orden no-discursivo a la idea de "enunciación", hecha lengua habitualmente por los lingüistas, quienes introducen un conjunto de dimensiones maquínicas que también dan lugar a la subjetividad. 
De este modo, ya no solo la familia, la escuela y la iglesia, en calidad de componentes semiológicos significantes y disciplinares por excelencia, serían los únicos llamados a producir sujetos, también se harían de ello cargo componentes de origen semiológico heterogéneo, incluso de tipo a-significante, que es a lo que Lewkowicz llama subjetividad massmediática. Esto justificaría el interés de diversos sectores por las producciones semióticas de los mass media, con el añadido de que tales producciones privilegian - a diferencia de la lingüística que la excluye- la dimensión afectivo-corporal, social, ética y política que Guattari (1996) asume como motor de la enunciación (Lazzarato, 2007).

En ese orden de ideas, podría decirse que lo educativo comienza a ser presa de muy diversos discursos cuya lógica entronca de modo perfecto con el régimen securitario, en tanto este propende por garantizar libertades, favorecer la circulación, y vencer las restricciones de tiempo y espacio, todo lo cual termina por comulgar con aquellos planteamientos que, a su vez, parapetados en la consigna de la sociedad de la información y la comunicación, pregonan la importancia del aprendizaje para toda la vida y desde cualquier lugar, minimizando en consecuencia el lugar del maestro y de la enseñanza en la escuela. Y por esa vía, el lugar mismo de la disciplina, de la cual denuestan ahora los discursos contemporáneos en pedagogía que abogan por renunciar al hábito y la costumbre, creyendo con ello que arribarán por fin - en virtud de sus nuevas apuestas formativas - al ideal de libertad al que, consideran, la escuela tradicional se opone; sin advertir la paradoja de los efectos que esta última suscitó tiempo atrás al haber querido producir seres disciplinables: nada más y nada menos que sujetos revolucionarios.

Por lo tanto, ante las postrimerías de lo disciplinar y el advenimiento de lo securitario, ¿qué esperar en materia educativa? De seguro, poco porque justamente lo que el hombre hace es ejercitarse con arreglo a ciertas técnicas y prácticas cuya finalidad no es otra que la de producirse. Sin embargo, ¿cuán al tanto estamos de los fines que persiguen las actuales técnicas securitarias, promovidas por el mercado? ¿Al servicio de qué educamos hoy y cómo? Recordemos que lo humano no deja de producirse y, en consecuencia, de producir efectos no previstos, no calculables que lo transforman aun a expensas de lo que se propone.

\section{Referencias}

Bauman, Z. (2007). Los retos de la educación en la modernidad líquida. Barcelona: Gedisa.

Dewey, J. (2010). Experiencia y Educación. Madrid: Biblioteca Nueva.

Guattari, F. (1996). Caosmosis. Buenos Aires: Manantial.

Kant, I. ([1803] 2003). Pedagogía. Madrid: Akal.

Lazzarato, M. (2007). La filosofía de la diferencia y el pensamiento menor. Bogotá: Universidad Central.

Leme Britto, L. (2010). Inquietudes y desacuerdos: la lectura más allá de lo obvio. Bogotá: Asolectura.

Lewkowicz, I. (2004). Escuela y ciudadanía. En: C. Corea e I. Lewkowicz (Eds.), Pedagogía del aburrido. Escuelas destituidas, familias perplejas (pp. 20-40). Buenos Aires, Argentina: Paidós.

Locke, J. ([1690] 2012). Pensamientos sobre la educación. Madrid: Akal.

Marín-Díaz, D. (2018). Disciplina, regla y norma: una mirada histórica al saber pedagógico. Ponencia presentada en el XIII CIHELA-Congreso Iberoamericano de Historia de la Educación Latinoamericana. Políticas, espacio público y disputas en la historia de la educación en América Latina. 28 de febrero al 3 de marzo del 2018.

Meirieu, P. (2010). Una llamada de atención. Madrid: Ariel.

Meirieu, P. (2016). Recuperar la pedagogía. De lugares comunes a conceptos claves. Buenos Aires: Paidós.

Noguera-Ramírez, C. (2012). El gobierno pedagógico. Del arte de educar a las tradiciones pedagógicas modernas. Bogotá: Siglo del Hombre.

Noguera-Ramírez, C. (2017). La formación como "antropotécnica”. Aproximación al concepto de Peter Sloterdijk. Pedagogía y Saberes, 47, 23-30.

Sloterdijk, P. (2012). Has de cambiar tu vida. Valencia: Pretextos.

Sloterdijk, P. (2015). Los hijos terribles de la modernidad. Madrid: Siruela.

Valenzuela, C. (2017). Derrida, herencia y educación. Pedagogía y saberes, 46, 77-83. 